\title{
A CIÊNCIA EM AÇÃO
}

Neste momento histórico estamos vivenciando a pandemia do Covid-19 (do inglês Coronavirus Disease 2019), para a qual ainda não temos profilaxia. No mundo inteiro instituições de fomento à pesquisa publicam editais conclamando cientistas a se reunirem para encontrar respostas em nível de antecipação (vacina) ou terapia. E no Brasil não tem sido diferente.

Em texto para a coluna $A$ hora da ciência (0 Globo, 8/5/2020), Patricia Rocco ${ }^{1}$ lembrou que "A ciência brasileira é excelente e sempre solidária [e] jamais desiste". Participante ativa nos grupos internacionais, a comunidade científica brasileira também está recebendo incentivos à participação em editais de pesquisa e formação científica, como mostra um levantamento do Departamento de Biblioteconomia da Universidade Federal do Rio de Janeiro², que compartilhamos a seguir:

- Na Fundação Oswaldo Cruz

Programa Inova Fiocruz - Edital Geração de Conhecimento - Enfrentamento da Pandemia e Pós-

Pandemia Covid-19

Edital Fiocruz - Profissionais para enfrentamento do Covid-19 - Diversas áreas

Programa Inova Fiocruz - Edital Ideias e Produtos Inovadores - Covid-19

ConVid Pesquisa de Comportamentos

Covid-19: Chamada pública para apoio a ações emergenciais junto a populações vulneráveis

ENSP - Chamada emergencial de mestrado e doutorado para auxiliar combate à Covid-19

IOC - Chamada para mestrado e doutorado em medicina tropical com foco em Covid-19

\section{- No CNPq}

Chamada MCTIC/CNPq/FNDCT/MS/SCTIE/Decit N ${ }^{0}$ 07/2020 - Pesquisas para enfrentamento da COVID-19, suas consequências e outras síndromes respiratórias agudas graves

- Na Capes

Programa Combate às Epidemias - Programa Estratégico Emergencial de Prevenção e Combate a Surtos, Endemias, Epidemias e Pandemias

Bolsas para a pesquisa do coronavírus

- Na Faperj

CHAMADA: Ação Emergencial Projetos para Combater os Efeitos da Covid-19 - Parceria Faperj/ Ses -2020

1 Médica, Professora Titular do Instituto de Biofísica Carlos Chagas Filho, da Universidade Federal do Rio de Janeiro, e membro da Rede-Virus, do Ministério da Ciência, Tecnologia, Inovação e Comunicação.

2 Realizado pelo aluno de graduação em Biblioteconomia Marcus Guimarães, sob orientação do Prof. Gustavo Freire. 
- Na Fapesp

Edital de Pesquisa para o Desenvolvimento de Tecnologias para Produtos, Serviços e Processos para 0 Combate à Doença por Corona Virus

Chamada de propostas de pesquisa - Suplementos de Rápida Implementação contra COVID-19

Chamada Desenvolvimento de terapêutica e diagnóstico para combater infecções por coronavírus

- Na Fapesq

Edital para rápida implementação de soluções de monitoramento, análise e recomendações frente à pandemia do COVID-19, no Estado da Paraíba. Com a Secretaria de Estado da Educação e da Ciência e Tecnologia da Paraíba. Encerrado com 10 projetos aprovados. ${ }^{3}$

Além dos recursos para a atividade da ciência em si, também estão sendo disponibilizadas fontes de informação científica, que constituem o corpus do "conhecimento em ação", conforme proposto por Wersig (1993) ${ }^{4}$ como objeto de estudo da Ciência da Informação. A Fiocruz, a FAPESP e 0 IBICT se destacam nesse sentido, disponibilizando observatórios, diretórios, portais, painéis, formação científica, monitoramento de dados e até uma plataforma wiki sobre o Covid-19. ${ }^{5}$

Nesse contexto colaborativo, a Agência de Inovação Tecnológica da Universidade Federal da Paraíba está mapeando iniciativas, tecnologias e projetos em curso dentro da universidade, relacionados ao Covid-19-19, e divulgando em sua página institucional o link para o painel do Ministério da Saúde sobre o tema. ${ }^{6}$ E o Portal do Laboratório de Tecnologias Intelectuais - LTi, está publicando uma página com fontes de informação sobre a temática. ${ }^{7}$

A ciência se move na direção da compreensão e da cura para o Covid-19 e a pesquisa científica brasileira caminha junto, pari passu com a pesquisa mundial. A Ciência da Informação, como estamos observando, também se junta a esse esforço comum para a criação e o compartilhamento de um conhecimento que pode significar a manutenção da vida no planeta Terra.

Estamos juntos!

Gustavo Henrique de Araújo Freire

Isa Maria Freire

Editores

3 Disponível em: http://fapesq.rpp.br/noticias/fapesq-divulga-resultado-final-e-seleciona-10-propostas-no-edital-covid-19/view. Acesso em 8 maio 2020.

4 WERSIG, G. Information science: the study of postmodern knowledge usage. Information Processing and Management: an International Journal, v. 29, n. 2, p. 229-239, Mar./Apr. 1993.

5 As informações completas, com respectivos links de acesso, podem ser consultadas no anexo a este Editorial.

6 Disponível em: https://www.ufpb.br/.

7 Disponível em: https://www.lti.pro.br. 


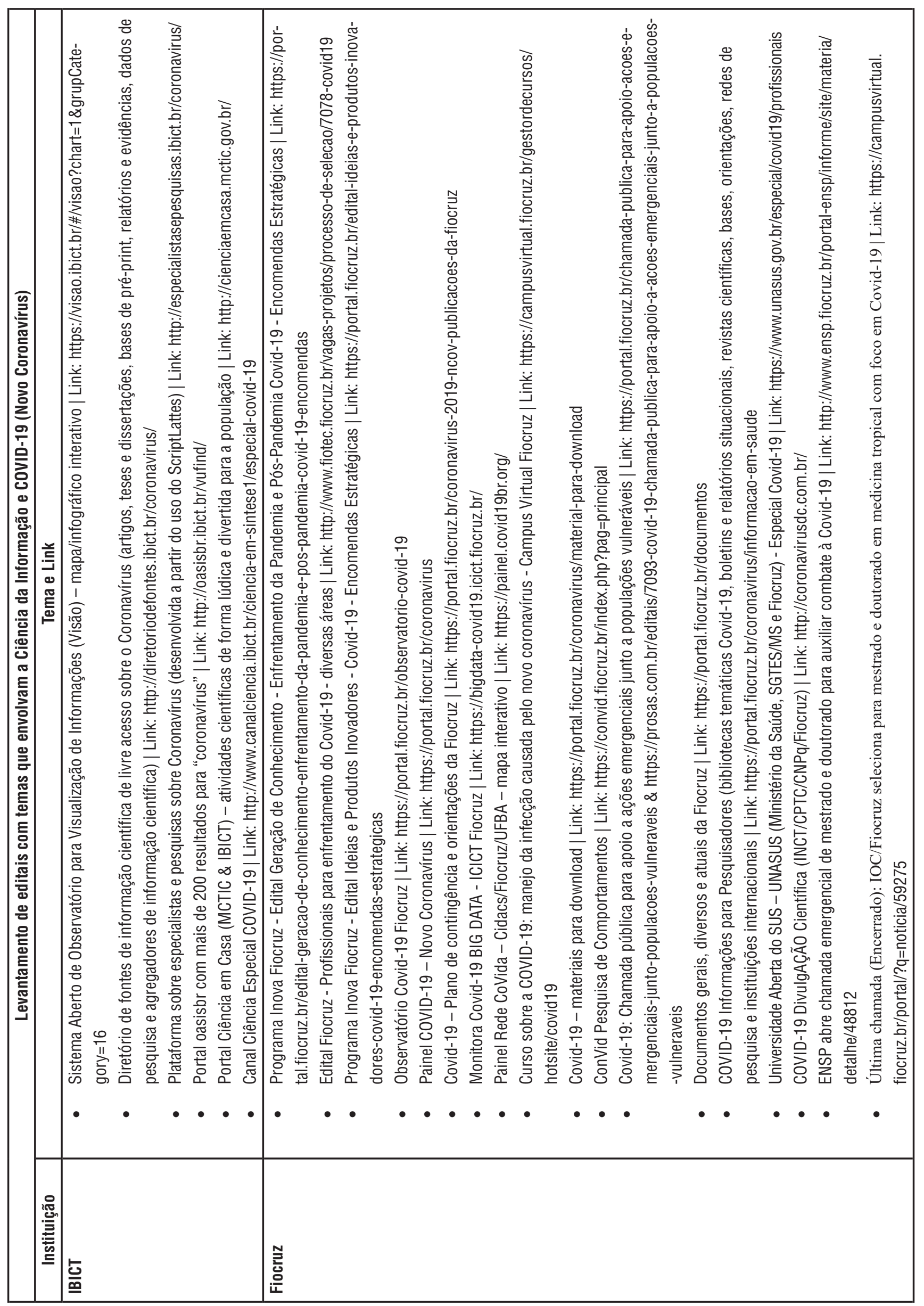




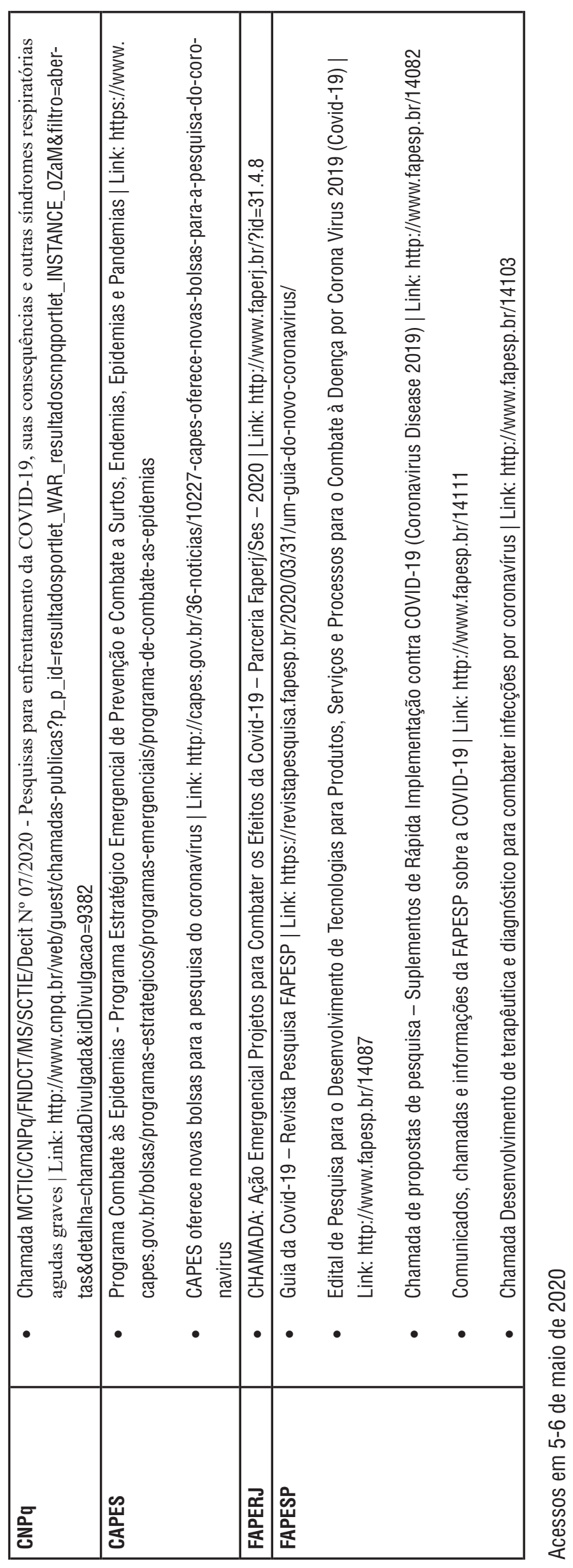

